8 Bachrach LL. The homeless mentally ill and the mental health services: an analytical review of the literature. In: Lamb HR, ed. The homeless mentally ill: a task force report of the American Psychiatric Association. Washington American Psychiatric Association, 1984:75-89.

9 Hogg L, Hall J, Marshall M. Assessing chronic mental patients: new approaches to assessing the movement of patients through care facilities. Psychosocial Rehahilitation fournal (in press
10 Krawiecka M, Goldberg D, Vaughn M. A standardised psychiatric assessment scale for rating chronic psychotic patients. Acta Psychiatr Scand 1977;55 299-308

11 Baker R, Hall JN. REHAB: a new assessment instrument for chronic psychiatric patients. Schizophr Bull 1988;14:97-111.

(Accepted 24 fuly 1989)

\title{
Use of medical record linkage to study readmission rates
}

\author{
J Henderson, M J Goldacre, M J Graveney, H M Simmons
}

\begin{abstract}
Readmission rates after inpatient care were studied by using routinely collected data from the Oxford record linkage study for $1968-85$. Discharges from hospital and subsequent admissions were identified for people who were both resident and treated in the area covered by the linkage study. Rates were calculated for readmissions within 28 days after discharge from the first, index event. Readmission rates for elective readmissions after elective index admissions rose from $3.5 \%$ in 1968 to $7 \cdot 1 \%$ in 1985 . Those for elective readmissions after immediate (emergency or accident) index admissions rose from $2.4 \%$ to $3.5 \%$ during the same period. Emergency readmissions after an immediate index admission rose from $4 \cdot 0 \%$ to $7 \cdot 0 \%$, and emergency readmissions after an elective index admission rose from $1 \cdot 3 \%$ to $2 \cdot 5 \%$. All these increases were significant. The rise in elective readmissions may in part reflect a trend towards planned discharge with the expectation of readmission. The rise in emergency readmissions, which has been fairly gradual over many years, may, in some cases, be due to pressure on resources and inappropriately short lengths of stay. Further evidence is required to confirm or refute this.
\end{abstract}

Readmission rates are one of the few potential measures available from routine statistics for assessing outcome, but due consideration must be given to issues of method and interpretation.

\section{Introduction}

Current interest in studying readmissions to hospital after discharge from inpatient care is due to several reasons. Firstly, hospital admission rates in England have increased for many years, but as routine hospital statistics are based on unlinked counts of admissions the extent to which these statistics are inflated by an increase in readmissions rather than primary admissions is generally unknown. Information about readmissions is therefore required to distinguish between changes in admission rates due to a change in numbers of patients treated and those due to a change in multiple admissions per person. Secondly, readmission is one measure of prognosis routinely available data on readmission rates for patients in particular diagnostic groups may be useful to clinicians in predicting the course of patients' illnesses. Thirdly, if patients who are at high risk of unintended readmission can be identified approaches to their care may be implemented that reduce the likelihood of readmission..$^{2-6}$

There has also been interest in the use of readmission rates as possible indicators of quality of care. Two admissions for an individual patient may or may not be related. When they are related the readmission may be planned as part of a programme of phased care or it may be unforeseen. Unforeseen readmissions may be a consequence of the natural course of the patient's disease or may result from suboptimal care during the first admission. Because of the second possibility variation in quality of care, either over time or between different hospitals, might result in variation in readmission rates. The package of performance indicators currently used in the NHS has been criticised for its lack of outcome indicators, ${ }^{78}$ and in the search for outcome indicators that could be obtained from routinely collected statistics the use of readmission rates is under consideration. ${ }^{9}$

The National Steering Group on Health Services Information (the Körner committee) recommended the use of a unified district medical record system so that each patient treated within a district would have the same medical record number for each admission. ${ }^{10}$ The use of this number in the computerised abstract of the hospital admission is intended to facilitate the linkage of episodes in hospital for individual patients within a district. Now that health authorities are implementing the recommendations of the Körner committee the means will exist to calculate readmission rates for the various purposes described above.

We analysed readmission rates by using data from the Oxford record linkage study for 1968-85. We report some broad trends in these rates and discuss some of the methodological issues that need consideration in analysing readmission rates.

\section{Population and methods}

The Oxford record linkage study includes brief abstracts of hospital inpatient records. These are similar to the abstracts that have been collected elsewhere in England as Hospital Activity Analysis in the past and that are collected currently as the Hospital Episode System. For many years these data have been collected in the Oxford region in ways such that records relating to the same patient can be linked together. ${ }^{112}$ These data have been collected in two of the eight health districts in the Oxford region since 1968 (population about 850000) and in six of the districts since 1975 (population about 1.9 million). The data presented here cover hospital discharges for 1968-85 in all specialties except psychiatry and obstetrics.

We used the following definitions and criteria for selection of records. An index event in each year was defined as the first recorded admission and subsequent discharge for each patient in the year. First discharges for a patient within a calendar year were excluded if the patient's admission occurred within 28 days after a discharge in the previous year (identified by linking records for each patient back to the previous year). Index events longer than 28 days in duration were excluded. Patients who died during the index event or the following 28 days were excluded. The time period for readmission was taken as being within 28 days after the date of discharge from the index event. When a patient had several readmissions only the first was tabulated. The analysis was confined to patients who 
were resident and treated in the study areas. Index events were grouped as immediate admissions (emergency and accident admissions) or elective admissions (from waiting list, booked admissions, and booked readmissions). A small number of admissions in other categories - notably, babies born in hospital-were excluded. If an index event ended in a transfer to another hospital the second episode was linked to the
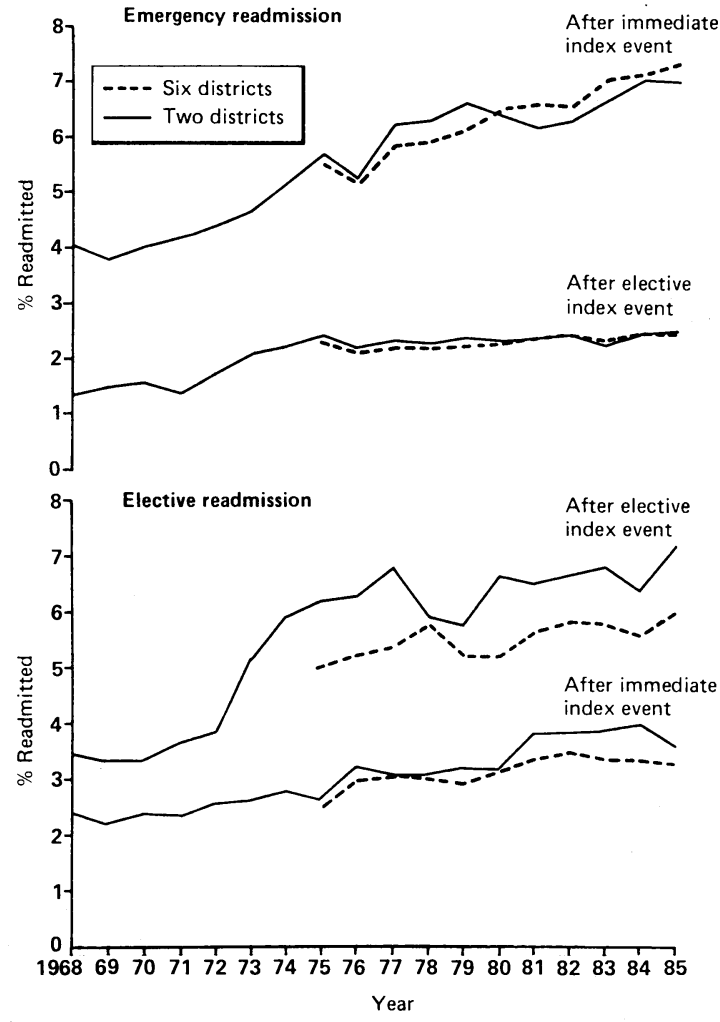

Emergency and elective readmission rates in two districts (1968-85) and six districts (1975-85). Readmission within 28 days after index event

TABLE I-Readmissions within 28 days after discharge from index event. Average readmission rates and average annual percentage increase in readmission rates in two populations, 1968-85 and 1975-85

\begin{tabular}{|c|c|c|c|c|}
\hline Type of index event and readmission & $\begin{array}{l}\text { No of index } \\
\text { cases } \\
\text { (thousands) }\end{array}$ & $\begin{array}{c}\text { Average } \\
\text { annual } \\
\text { readmissions/ } \\
100\end{array}$ & $\begin{array}{c}\% \text { Increase in } \\
\text { rate/year }\end{array}$ & $\begin{array}{c}95 \% \\
\text { Confidence } \\
\text { interval of } \\
\text { increase }\end{array}$ \\
\hline \multicolumn{5}{|c|}{ Immediate index, emergency readmission: } \\
\hline $1968-85$ & 451 & $5 \cdot 5$ & $3 \cdot 8$ & $3 \cdot 5$ to $4 \cdot 0$ \\
\hline $1975-85$ & 681 & $6 \cdot 2$ & $3 \cdot 2$ & 2.8 to 3.5 \\
\hline \multicolumn{5}{|l|}{ Elective index, emergency readmission: } \\
\hline $1968-85$ & 600 & $2 \cdot 1$ & $3 \cdot 2$ & $2 \cdot 8$ to 3.6 \\
\hline $1975-85$ & 856 & $2 \cdot 2$ & $1 \cdot 2$ & 0.7 to 1.7 \\
\hline \multicolumn{5}{|l|}{ Elective index, elective readmission: } \\
\hline $1968-85$ & 600 & $5 \cdot 4$ & $4 \cdot 6$ & $4 \cdot 3$ to $4 \cdot 8$ \\
\hline $1975-85$ & 856 & $5 \cdot 3$ & 1.8 & $1 \cdot 4$ to $2 \cdot 1$ \\
\hline \multicolumn{5}{|l|}{ Immediate index, elective readmission: } \\
\hline $1968-85$ & 451 & $3 \cdot 0$ & $3 \cdot 3$ & 3.0 to 3.7 \\
\hline 1975-85 & 681 & $3 \cdot 0$ & 1.9 & 1.5 to $2 \cdot 4$ \\
\hline
\end{tabular}

*Annual percentage increase in readmissions per year per 100 index events calculated from slope of fitted line. $t \mathrm{p}<0 \cdot 05$. first and was considered as an extension of the index stay rather than a readmission. If the total length of stay of the conjoined episodes exceeded 28 days the event was excluded from the analysis because it met the exclusion criterion on length of stay described above. Readmissions were grouped as emergencies or elective readmissions. In the analyses for each specialty the specialty was defined as that at the time of the patient's discharge from the index admission. Readmissions were defined as those to any specialty (excluding psychiatry and obstetrics).

Data are presented for trends in readmissions for all specialties combined in Oxfordshire and West Berkshire Health Authorities for 1968-85 and in the six districts covered by data collection for 1975-85. Data are also presented for individual specialties and for 24 groups of operations in the two districts for 1968-85. In comparing readmission rates over time we calculated unstandardised rates and rates standardised for age. We have shown age standardised rates here because they take account of changes in the age structure of the population of patients, though, in fact, the trends in the two rates were similar. We used the direct method of standardisation ${ }^{13}$ and took the total population for 1981 in each category as the standard population. Thus standardisation was undertaken in this way within categories of patients (that is, for all specialties combined, for each specialty, and for each operation). The percentage change in readmission rates per year and $95 \%$ confidence intervals were calculated by logistic regression by using generalised linear interactive modelling (GLIM).

\section{Results}

Table I summarises the average readmission rates within 28 days after discharge from the index event during the time period and average annual percentage changes in readmission rates for all specialties combined. Readmission rates in each category increased significantly over time $(p<0.05)$. The steepest rise during 1968-85 was in elective readmissions after elective index events. Readmissions in this category averaged $5 \cdot 4$ per 100 and rose from $3 \cdot 5$ to $7 \cdot 1$ per 100 elective events from 1968 to 1985 . Elective readmission rates after an immediate index event averaged 3.0 per 100 and rose from $2 \cdot 4$ to 3.5 per 100 index events. Emergency readmission rates after an immediate index event averaged 5.5 readmissions per 100 events and rose from $4 \cdot 0$ to $7 \cdot 0$ per 100 index events. Emergency readmission rates after an elective index event averaged $2 \cdot 1$ per 100 and rose from 1.3 to 2.5 per 100 index events. The figure shows the year by year changes in the two districts for 1968-85 and in the six districts for 1975-85.

Table II summarises trends in emergency readmission rates after discharge from immediate and elective index events in each main specialty. Emergency readmission rates significantly increased over time in most specialties. Table III summarises trends in

TABLE II -Emergency readmissions within 28 days after discharge from index events. Average readmission rates and average annual percentage increase in readmission rates, $1968-85$

\begin{tabular}{|c|c|c|c|c|c|c|c|c|}
\hline \multirow[b]{2}{*}{ Specialty } & \multicolumn{4}{|c|}{ After immediate index event } & \multicolumn{4}{|c|}{ After elective index event } \\
\hline & $\begin{array}{c}\text { No of } \\
\text { index cases }\end{array}$ & $\begin{array}{c}\text { Readmissions/ } \\
100\end{array}$ & $\begin{array}{c}\% \text { Increase in } \\
\text { rate/year }\end{array}$ & $\begin{array}{l}95 \% \text { Confidence } \\
\text { interval of } \\
\text { increase }\end{array}$ & $\begin{array}{c}\text { No of } \\
\text { index cases }\end{array}$ & $\begin{array}{c}\text { Readmissions/ } \\
100\end{array}$ & $\begin{array}{l}\text { \% Increase in } \\
\text { rate/year }\end{array}$ & $\begin{array}{l}95 \% \text { Confidence } \\
\text { interval of } \\
\text { increase }\end{array}$ \\
\hline General medicine & 119376 & $7 \cdot 2$ & $3 \cdot 5$ & $3 \cdot 0$ to $4 \cdot 0^{\star}$ & 41274 & $4 \cdot 6$ & $1 \cdot 6$ & 0.7 to $2 \cdot 6^{\star}$ \\
\hline General surgery & 94248 & $5 \cdot 3$ & $3 \cdot 8$ & $3 \cdot 2$ to $4 \cdot 4^{\star}$ & 179046 & 1.9 & $3 \cdot 6$ & $2 \cdot 9$ to $4 \cdot 3^{\star}$ \\
\hline Geriatrics & 9522 & $9 \cdot 7$ & 1.9 & $0 \cdot 5$ to $3 \cdot 4^{\star}$ & 11772 & $4 \cdot 3$ & $-0 \cdot 2$ & $-2 \cdot 2$ to 1.9 \\
\hline Paediatrics & 51138 & $5 \cdot 6$ & $3 \cdot 9$ & $3 \cdot 1$ to $4 \cdot 8^{\star}$ & 6084 & $4 \cdot 2$ & $7 \cdot 5$ & $4 \cdot 8$ to $10 \cdot 3^{\star}$ \\
\hline Otorhinolaryngology & 8136 & $4 \cdot 4$ & $2 \cdot 1$ & $0 \cdot 1$ to $4 \cdot 3^{\star}$ & 79200 & $1 \cdot 3$ & $0 \cdot 0$ & -1.2 to 1.2 \\
\hline Gynaecology & 37728 & $5 \cdot 6$ & $4 \cdot 2$ & $3 \cdot 3$ to $5 \cdot 1^{\star}$ & 120852 & $1 \cdot 7$ & $2 \cdot 1$ & $1 \cdot 2$ to $3 \cdot 1^{\star}$ \\
\hline Trauma and orthopaedic surgery & 92196 & $2 \cdot 0$ & $0 \cdot 0$ & -0.9 to 0.9 & 55530 & $1 \cdot 2$ & $2 \cdot 4$ & $0 \cdot 8$ to $3 \cdot 9^{\star}$ \\
\hline Ophthalmology & 7884 & $3 \cdot 7$ & $5 \cdot 1$ & $2 \cdot 6$ to $7 \cdot 7^{\star}$ & 26712 & 1.5 & $2 \cdot 6$ & 0.6 to $4 \cdot 6^{\star}$ \\
\hline Radiotherapy & 2772 & $20 \cdot 1$ & 0.8 & $-1 \cdot 1$ to $2 \cdot 8$ & 6984 & 7.9 & $9 \cdot 0$ & $7 \cdot 1$ to $10 \cdot 9 \star$ \\
\hline Plastic surgery & 756 & $2 \cdot 9$ & $3 \cdot 8$ & -5.9 to 14.6 & 8712 & $1 \cdot 6$ & $4 \cdot 1$ & 0.7 to $7 \cdot 6^{\star}$ \\
\hline General practitioner beds & 14166 & $8 \cdot 5$ & $3 \cdot 6$ & 2.3 to 4.9 * & 15300 & $4 \cdot 2$ & $2 \cdot 6$ & 0.6 to $4.7^{\star}$ \\
\hline
\end{tabular}




\begin{tabular}{|c|c|c|c|c|c|c|c|c|}
\hline \multirow[b]{2}{*}{ Specialty } & \multicolumn{4}{|c|}{ After immediate index event } & \multicolumn{4}{|c|}{ After elective index event } \\
\hline & $\begin{array}{l}\text { No of } \\
\text { index cases }\end{array}$ & $\begin{array}{c}\text { Readmissions/ } \\
100\end{array}$ & $\begin{array}{l}\% \text { Increase in } \\
\text { rate/year }\end{array}$ & $\begin{array}{l}95 \% \text { Confidence } \\
\text { interval of } \\
\text { increase }\end{array}$ & $\begin{array}{c}\text { No of } \\
\text { index cases }\end{array}$ & $\begin{array}{c}\text { Readmissions/ } \\
100\end{array}$ & $\begin{array}{l}\% \text { Increase in } \\
\text { rate/year }\end{array}$ & $\begin{array}{l}95 \% \text { Confidence } \\
\text { interval of } \\
\text { increase }\end{array}$ \\
\hline General medicine & 119376 & 3.0 & $2 \cdot 9$ & $2 \cdot 2$ to $3 \cdot 6^{\star}$ & 41274 & $10 \cdot 2$ & $2 \cdot 2$ & 1.5 to $2.9^{\star}$ \\
\hline $\begin{array}{l}\text { General surgery } \\
\text { Ge }\end{array}$ & 94248 & $3 \cdot 2$ & $4 \cdot 2$ & $3 \cdot 4$ to $5 \cdot 0$ * & 179046 & 3.0 & 1.6 & $1 \cdot 1$ to $2 \cdot 2^{\star}$ \\
\hline Geriatrics & 9522 & $6 \cdot 7$ & 0.8 & -0.8 to 2.5 & 11772 & $57 \cdot 1$ & $8 \cdot 6$ & $7 \cdot 7$ to $9 \cdot 6^{\star}$ \\
\hline Paediatrics & 51138 & $1 \cdot 3$ & -0.5 & $-2 \cdot 0$ to $1 \cdot 0$ & 6084 & $6 \cdot 7$ & 6.5 & $4 \cdot 3$ to $8 \cdot 7^{\star}$ \\
\hline Otorhinolaryngology & 8136 & $3 \cdot 0$ & $2 \cdot 5$ & $0 \cdot 1$ to $5 \cdot 1^{\star}$ & 79200 & 1.9 & $2 \cdot 6$ & $1 \cdot 6$ to $3 \cdot 6^{\star}$ \\
\hline Gynaccology & 37728 & $2 \cdot 5$ & $2 \cdot 9$ & 1.6 to $4.3^{\star}$ & 120852 & $2 \cdot 3$ & -0.5 & $-1 \cdot 2$ to $0 \cdot 2$ \\
\hline Trauma and orthopaedic surgery & 92196 & $2 \cdot 7$ & $3 \cdot 5$ & $2 \cdot 7$ to $4 \cdot 4^{\star}$ * & 55530 & $4 \cdot 6$ & $0 \cdot 8$ & $0 \cdot 1$ to $1.6^{\star}$ \\
\hline Ophthalmology & 7884 & $4 \cdot 0$ & 0.9 & -1.4 to $3 \cdot 2$ & 26712 & $2 \cdot 8$ & $-0 \cdot 8$ & $-2 \cdot 2$ to $0 \cdot 6$ \\
\hline Radiotherapy & 2772 & $20 \cdot 4$ & $3 \cdot 7$ & $1 \cdot 7$ to $5 \cdot 8^{\star}$ & 6984 & $23 \cdot 2$ & $7 \cdot 7$ & $6 \cdot 6$ to $8 \cdot 9^{\star}$ \\
\hline Plastic surgery & 756 & $7 \cdot 1$ & $9 \cdot 2$ & $2 \cdot 1$ to $16 \cdot 8^{\star}$ & 8712 & 3.9 & $3 \cdot 0$ & $0 \cdot 8$ to $5 \cdot 2^{\star}$ \\
\hline General practitioner beds & 14166 & $3 \cdot 7$ & $7 \cdot 5$ & 5.5 to $9.5^{*}$ & 15300 & $26 \cdot 1$ & $6 \cdot 4$ & 5.5 to $7.5^{\star}$ \\
\hline
\end{tabular}

TABLE IV - Emergency readmissions within 28 days after discharge from index event. Average readmission rates and average annual increase in readmission rates, $1968-85$

\begin{tabular}{|c|c|c|c|c|c|}
\hline Operation & OPCS code & $\begin{array}{c}\text { No of } \\
\text { index cases }\end{array}$ & Readmissions $/ 1000$ & $\begin{array}{l}\text { \% Increase in } \\
\text { rate/year }\end{array}$ & $\begin{array}{l}95 \% \text { Confidence } \\
\text { interval of increase }\end{array}$ \\
\hline Correction of squint & $110,112-5$ & 7398 & $5 \cdot 0$ & -0.5 & $-6 \cdot 6$ to $6 \cdot 0$ \\
\hline For cataract & $170,172-4,176,178-9$ & 10278 & $16 \cdot 0$ & $3 \cdot 3$ & 0.3 to $6 \cdot 3^{\star}$ \\
\hline Myringotomy & 193 & 18666 & $5 \cdot 7$ & $0 \cdot 3$ & -3.9 to 4.8 \\
\hline Repair of inguinal hernia & 411 & 23130 & $11 \cdot 3$ & $6 \cdot 7$ & $4 \cdot 2$ to $9 \cdot 3^{\star}$ \\
\hline Mastectomy & $381-5$ & 13590 & $7 \cdot 5$ & $4 \cdot 4$ & 0.5 to $8.4^{\star}$ \\
\hline Gastrectomy & $422-3$ & 1674 & $16 \cdot 2$ & $6 \cdot 7$ & -0.6 to 14.5 \\
\hline Appendicectomy & $441-4$ & 23544 & $24 \cdot 8$ & $5 \cdot 5$ & $3 \cdot 9$ to $7 \cdot 2^{\star}$ \\
\hline Colectomy & $460-1$ & 3468 & $21 \cdot 7$ & $9 \cdot 5$ & $4 \cdot 3$ to $15 \cdot 0^{\star}$ \\
\hline Abdominoperineal excision of rectum & 472 & 1152 & $10 \cdot 2$ & $2 \cdot 2$ & $-10 \cdot 5$ to $16 \cdot 7$ \\
\hline On haemorrhoids & $490-5$ & 5004 & $13 \cdot 3$ & $0 \cdot 3$ & $-4 \cdot 0$ to $4 \cdot 8$ \\
\hline Cholecystectomy & 522 & 10512 & $13 \cdot 6$ & $3 \cdot 7$ & $0 \cdot 3$ to $7 \cdot 2^{\star}$ \\
\hline Prostatectomy & $630-4$ & 8730 & $34 \cdot 7$ & $8 \cdot 4$ & 5.9 to $11 \cdot 0^{\star}$ \\
\hline Excision or repair of hydrocele & 644 & 2502 & $11 \cdot 8$ & $5 \cdot 5$ & -1.8 to 13.4 \\
\hline Vasectomy & 651 & 6210 & $4 \cdot 2$ & $-1 \cdot 2$ & $-9 \cdot 7$ to $8 \cdot 1$ \\
\hline Female sterilisation & 684,687 & 12798 & $7 \cdot 8$ & $-2 \cdot 9$ & $-7 \cdot 7$ to $2 \cdot 3$ \\
\hline Circumcision & 661 & 8820 & $13 \cdot 3$ & 4.9 & $1 \cdot 1$ to $8 \cdot 9$ * \\
\hline Dilatation and curettage & $703-4$ & 43056 & $11 \cdot 8$ & $0 \cdot 3$ & $-1 \cdot 4$ to $2 \cdot 1$ \\
\hline Termination of pregnancy & 742 & 18504 & $25 \cdot 6$ & $1 \cdot 3$ & -0.7 to $3 \cdot 4$ \\
\hline Total hip replacement & 810 & 7380 & $7 \cdot 9$ & $11 \cdot 4$ & $5 \cdot 0$ to $18 \cdot 1^{\star}$ \\
\hline Other arthroplasty of hip & 811 & 1890 & $9 \cdot 8$ & $10 \cdot 0$ & $-5 \cdot 5$ to $28 \cdot 1$ \\
\hline Excision of semilunar cartilage of knee & 820 & 5058 & $7 \cdot 0$ & $11 \cdot 3$ & $4 \cdot 2$ to $18 \cdot 9 \star$ \\
\hline On varicose veins & $890-8$ & 9594 & $7 \cdot 3$ & $4 \cdot 6$ & $-0 \cdot 1$ to $9 \cdot 5$ \\
\hline Excision of superficial cyst & 912 & 5544 & $2 \cdot 6$ & $11 \cdot 5$ & -0.4 to $24 \cdot 8$ \\
\hline Removal of nail structures & 928 & 6372 & $5 \cdot 8$ & $-4 \cdot 8$ & $-10 \cdot 6$ to $1 \cdot 4$ \\
\hline
\end{tabular}

${ }^{\star} \mathrm{p}<0 \cdot u s$. TOffice of Population Censuses and Surveys operation code, third revision.

elective readmission rates after immediate and elective index events in each main specialty. As with emergency readmissions, elective readmission rates significantly increased over time in most specialties, particularly after elective index events. Table IV shows emergency readmission rates within 28 days of discharge after a range of common operations. Among the operations studied the highest emergency readmission rates occurred after prostatectomy. termination of pregnancy, appendicectomy, and colectomy. Emergency readmission rates increased over time in 20 of the 24 operations, being significant $(p<0.05)$ in 10 of these.

\section{Discussion}

The application of routinely collected numerical information to describe, monitor, and assess patterns of use of hospital care is increasingly emphasised. In particular the implementation of the Körner recommendations on hospital information systems, ${ }^{10}$ the introduction of performance indicators, ${ }^{14}$ and the publication of the white paper on the NHS ${ }^{15}$ have all added impetus to this. The Körner recommendations on district numbering systems mean that it should now be possible to link together successive records of hospital care for individual patients within a district and therefore to calculate readmission rates. There is interest in the use of readmission rates as possible indicators of outcome for comparisons over time and among hospitals. ${ }^{9}$ The ability to link hospital records for individual patients within a district also provides a means, more generally, of studying patterns of care entailing multiple admissions per person and for clinicians to estimate the probability of readmission for defined groups of patients-for example, after particular operations. The fact that such linkage will be possible only for episodes of care within a district, however, means that in districts where there is substantial cross boundary care it will be possible to construct only a partial picture of readmission rates from routine statistics.

\section{METHODOLOGICAL ISSUES}

Present experience in the analysis of readmission rates with time sequenced routine data is limited, and some of the methodological issues and decisions that need to be made are detailed in the appendix. These will generally need to be considered in any study of readmission rates based on routine data; but the decisions made on some issues may inevitably be somewhat arbitrary. In addition to the points covered in the appendix, decisions are needed on selecting and grouping index events and readmissions according to specialties, diagnoses, and operations. We were interested in broad questions - whether readmission rates had risen generally - as well as in the analysis of readmission rates for selected conditions. Analysis of readmission rates for individual conditions will probably be more readily interpretable than those for a specialty or a district as a whole, but a corollary is that it may be difficult to extrapolate from data on a few conditions to draw general conclusions about trends over time or geographical variation in readmission rates. The possibility of calculating readmission rates standardised for index condition merits consideration. Decisions are also needed on whether to confine the selection of readmissions to a limited number of 
clinical categories and, in particular, to select the diagnoses at readmission that suggest that the readmission may be closely related to the index event. This also merits consideration, but there are difficulties in using the International Classification of Diseases and the current standard ways of recording data to define groups of conditions that are likely to be associated with index events and those that are not.

Interpretation of variation in readmission rates includes the fact that decisions to readmit are influenced not only by patients' clinical states but also by clinicians' thresholds for readmission and the availability of beds. Possibly in some circumstances readmission rates may be inappropriately low if facilities for patients who require inpatient care at follow up cannot readily be found.

\section{TRENDS IN THE OXFORD REGION, 1968-85}

We have shown that readmission rates have risen overall in all specialties and for most of the 24 operations studied. The pattern and scale of the rise in emergency readmissions were similar when we compared the two districts studied from 1968 to 1985 with the six districts studied from 1975 to 1985 . An increase in readmission rates for elective readmissions was expected; at least in the medical care of the elderly, policies of shortening lengths of stay, planned discharge, and planned readmission have been used increasingly.

The rise in emergency readmission rates was less predictable. Drawing conclusions from our results about the relation between rising readmission rates and care during the index admissions is difficult. On one hand, the results are consistent with the suggestion that pressure on resources and decreasing lengths of stay may have led, in certain cases, to inappropriately early discharge necessitating emergency readmission. Lengths of stay in the Oxford region are shorter than those in most other regions, and, as elsewhere, they have declined steadily in all specialties over the years covered by this study. On the other hand, we have shown that readmission rates are no higher after planned day case surgery than after conventional inpatient care for several surgical conditions. ${ }^{16}$ Patients who undergo day case care are a clinically selected subgroup of patients, and their experience of readmission is not necessarily applicable to more general shortening of lengths of stay. We are undertaking further work on prognostic factors for readmission, including lengths of stay. Changes in treatment and other aspects of management, in addition to shortening lengths of stay, will also have occurred during the period. The increases in emergency readmission rates have been fairly gradual over a long period.

Obvious refinements to the approach we have taken so far include, firstly, studies of samples of case notes to determine whether individual emergency readmissions may have been related to care during the index event. Secondly, further exploration of routinely linked statistical data could be undertaken - for example, by studying different time intervals from discharge to readmission, readmission rates in relation to lengths of stay, and particular combinations of diagnoses in the index admission and readmission.

Few "benchmarks" exist against which we may judge our findings. Comparable data from other parts of the country would be useful to determine whether there is much geographical variation in current readmission rates and in trends over time. The philosophy underpinning the national use of performance indicators has been to regard them as a "sieve" to indicate subjects worthy of further study. ${ }^{1+}$ The expectations have been that no one indicator may be indicative of good or bad care but that arrays of indicators in combination or studies prompted by unexpected findings from routine indicators may give insight into variation in standards of care. With due consideration given to issues of method and interpretation we suggest that readmission rates, as one of the few potential measures of outcome now available from routine statistics, may have a place in the array of performance indicators. They merit further investigation in this respect.

The unit of clinical epidemiology is part of the department of community medicine and general practice, University of Oxford. The unit is funded by the Department of Health, and the Oxford record linkage study is funded by Oxford Regional Health Authority.

\section{Appendix}

SOME METHODOLOGICAL CONSIDERATIONS IN ANALYSING READMISSION RATES

(1) Analyses of trends over time require a means of dividing time into discrete periods. We chose the first recorded discharge within a calendar year. In any time sequenced system of records, however, the first recorded event may not necessarily be the first relevant event. The patient's first relevant admission in a sequence of care may have occurred before the defined time period (for example, in the previous calendar year), before data began to be collected in the data system, or outside the area covered by the system.

(2) When data are available about admissions before the defined time period of interest - for example, before each calendar year - the option exists to exclude patients with prior admissions. For example, we decided to exclude index events falling within each calendar year if the patient had been discharged from hospital within the previous 28 days.

(3) We excluded patients who were treated within the area covered by the Oxford record linkage study but lived outside it. We did so on the grounds that non-residents were more likely than residents to have received some of their hospital care, either before our first record of admission or a subsequent readmission, outside the area. This consideration may be particularly relevant in the analysis of Körner data, in which linkage of episodes can be made only within a district. In the area covered by the Oxford record linkage study, with the means to link records across districts, this is generally less of a problem than it would be elsewhere.

(4) Index events should be excluded if they end in death because the patients are not at risk of readmission. It may be useful, however, to tabulate the number of index events that end in death and consider these in the overall interpretation of readmission rates - for example, if one hospital has higher death rates than another it may discharge fewer seriously ill patients at high risk of readmission.

(5) Decisions need to be made about index events that end in a transfer to another hospital. Conventionally, in health service statistics transfers between hospitals have counted as separate episodes of hospital care. Given the means to link records it becomes possible to convert transfers from discrete episodes of care into the continuous episodes of care that in reality they are. This is important because transfers would otherwise artificially inflate readmission rates. We therefore defined episodes entailing transfers as conjoined episodes of continuous care. In our experience analysis of data on events entailing transfers is not as straightforward as it might seem, and further details are available from us on request.

(6) The duration of the index event may be considered because patients with fairly long stays may be at a different risk of readmission from those with short stays. We excluded index events if the patient stayed longer than 28 days. We also applied this criterion to the total, conjoined stay of patients whose care entailed transfer.

(7) The time to readmission may be selected to begin at the date of the admission to, or discharge from, the index event or at the date of operation (if appropriate). There are arguments for and against each option. If the readmission period is counted from the date of admission rather than discharge a long length of stay decreases the risk of readmission because much of the period at risk is spent in hospital. If counted from discharge, when lengths of stay differ patients will probably be at different stages of recovery from the acute phase of illness.

(8) The time within which readmission is considered to occur needs definition. We chose 28 days after discharge 
(though we have also looked at other time intervals). This decision will also depend, to some extent, on the subject under study. For example, in monitoring the success of hip arthroplasties a much longer time period for readmission would be appropriate than in monitoring readmissions for infection after abdominal operations.

(9) If a patient is readmitted more than once after an index event a decision is needed on whether to count only the first readmission (as we did) or to count each subsequent readmission. Similarly, a decision is needed on whether a readmission should be counted as both a readmission and a new index event from which further readmissions might occur.

(10) Decisions are needed on whether and how to define different sources of admission for the index event and for readmissions. We grouped sources of admission for index events and readmissions as immediate or elective admissions. The recording of immediate and elective admissions may not be wholly uniform. Anecdote suggests that clinicians who wish to circumvent long waits for elective admissions may, on occasion, deem the patient to require emergency admission.

1 Goldacre MJ, Simmons H, Henderson J, Gill LE. Trends in episode based and person based rates of admission to hospital in the Oxford record linkage study area. Br Med f 1988;296:583-5.

2 Anderson GF, Steinberg EP. Predicting hospital readmissions in the Medicare population. Inquiry 1985;22:251-8
3 Roos LL, Cageorge SM, Roos NP, Danzinger R. Centralization, certification nd monitoring: readmissions and complications after surgery. Med Care 1986;24: 1044-66

4 Victor CR, Vetter NJ. The early readmission of the elderly to hospital. Age Ageing 1985;14:37-42.

5 Odetunde ZO. Early readmission of the elderly into hospital. Physiotherapy 1987;73:631-4

6 Williams EI, Fitton F. Factors affecting early unplanned readmission of elderly patients to hospital. Br Med f 1988;297:784-7.

7 Klein R. Performance, evaluation and the NHS: a case study in conceptual perplexity and organisational complexity. Public Administration 1982;60: $385-407$

8 Downe 1988;79:117-21. Health Service Indicators Group A report on Kömer indicators. London: Department of Health, 1988:9.

10 Steering Group on Health Services Information (chairman: Mrs E Körner) First report to the secretary of state. London: HMSO, 1982

11 Acheson ED. Medical record linkage. London: Oxford University Press, 1967. Acheson ED, Barr A. Multiple spells of in-patient treatment in a calendar year. British fournal of Preventive and Social Medicine 1965;19:182-91

13 Armitage P, Berry G. Statistical methods in medical research. 2nd ed. Oxford Blackwell Scientific, 1987;399-403.

14 Department of Health and Social Security. Performance indicators in the NHS London: DHSS, 1982. $(\mathrm{RA}(82) 34$.

15 Secretaries of State for Health, Wales, Northern Ireland, and Scotland. Working for patients. London: HMSO, 1989. (Cmnd 555.)

16 Henderson J, Goldacre MJ, Griffith M, Simmons HM. Day case surgery: geographical variation, trends and readmission rates. $\mathcal{f}$ Epidemiol Community Health (in press).

\title{
Psychological and social problems in HIV infection: interviews with general practitioners in London
}

\author{
Michael B King
}

\section{Abstract}

Objective-To assess current practice and opinions of general practitioners in London about managing psychological and social problems relating to HIV infection.

Design-A stratified random sample of general practitioners, including those with a range of experience of people with HIV infection, were interviewed by medically trained interviewers.

Setting-Doctors' surgeries.

Participants -270 General practitioners working within the area covered by London postcodes.

Results - Two thirds of doctors had treated at least one patient with HIV infection and described their work with these patients. General practitioners were counselling and educating many of their patients about AIDS and associated risk behaviours and were aware of the need for careful attention to confidentiality. Doctors with no experience of patients with HIV infection were often older, in singlehanded practice, less inclined to deal with drug abusers or to counsel their patients on risk behaviours, and more in favour of insurance companies' policies towards people with HIV infection.

Conclusions-General practitioners in London are quickly becoming involved in the care of patients with HIV infection and their relatives and friends. Many are counselling patients and testing for antibodies themselves and regard this as an integral part of their work. A considerable workload in primary care comprised patients who obsessively fear contracting HIV infection.

\section{Introduction}

"Familial and social rejection of homosexuals leaves many AIDS patients alone with their disease-and their physicians." With the growing prevalence of AIDS and the emphasis on providing care in the community the relationship between general practi- tioners and patients with HIV infection has become a focus of increasing interest. ${ }^{23}$ Although patients would prefer family doctors to take part in their care, they are reluctant to consult them out of fear of rejection or lack of confidentiality or because they do not consider their doctor knowledgeable about AIDS. ${ }^{+5}$ There have now been eight published surveys of the attitudes of general practitioners in Britain towards HIV infection, ${ }^{6-13}$ some of which entailed small numbers and all of which used postal questionnaires to deal with mainly public health issues. Only four included doctors in London, the city in Britain with the greatest concentration of people infected with HIV. Postal questionnaires are useful for an overview of attitudes but by relying on predominantly forced choice responses ultimately fail to deal with the complexitv of issues related to AIDS. ${ }^{9}$ If family doctors are to play a central part in the community care of patients with HIV infection ${ }^{1415}$ it is essential to identify and report their needs in preparing to meet this challenge. ${ }^{15}$

By interviewing a sample of London general practitioners in depth I aimed at assessing their current participation in the psychological and social problems of patients with HIV infection. These interviews took place three months after a postal survey in which all general practitioners in London were sent a questionnaire on numbers of patients with HIV infection under their care and their attitudes towards and knowledge of the psychological, social, and ethical problems of HIV infection. ${ }^{12}$

\section{Subjects and methods}

General practitioners working within the areas covered by London postcodes were selected for interview to obtain a group of doctors with a range of experience of HIV from those with no patients with HIV infection to those with considerable numbers. Doctors were chosen from the list of a commercial mailing company that regularly updated names and 